\title{
Emergence and clonal dissemination of carbapenem-hydrolysing OXA-58-producing Acinetobacter baumannii isolates in Bolivia
}

Correspondence

Lucía Gallego

lucia.gallego@ehu.es

Received 30 March 2011

Accepted 18 August 2011

\author{
Elena Sevillano, ${ }^{1}$ Elena Fernández, ${ }^{1}$ Zulema Bustamante, ${ }^{2}$ \\ Silvia Zabalaga, ${ }^{2}$ Ikerne Rosales, ${ }^{1}$ Adelaida Umaran ${ }^{1}$ and Lucía Gallego ${ }^{1}$ \\ ${ }^{1}$ Dpto Inmunología, Microbiología y Parasitología, Facultad de Medicina y Odontología, \\ Universidad del País Vasco, Campus de Bizkaia, B Sarriena s/n, 48940 Leioa (Bizkaia), Spain \\ ${ }^{2}$ Departamento de Bioquímica, Facultad de Bioquímica y Farmacia, Universidad Mayor de San \\ Simón, Avenida Aniceto Arce s/n, Cochabamba, Bolivia
}

\begin{abstract}
Acinetobacter baumannii is an emerging multidrug-resistant pathogen and very little information is available regarding its imipenem resistance in Latin American countries such as Bolivia. This study investigated the antimicrobial resistance profile of 46 clinical strains from different hospitals in Cochabamba, Bolivia, from March 2008 to July 2009, and the presence of carbapenemases as a mechanism of resistance to imipenem. Isolates were obtained from 46 patients (one isolate per patient; 30 males, 16 females) with an age range of 1 day to 84 years, and were collected from different sample types, the majority from respiratory tract infections (17) and wounds (13). Resistance to imipenem was detected in 15 isolates collected from different hospitals of the city. These isolates grouped into the same genotype, named $A$, and were resistant to all antibiotics tested including imipenem, with susceptibility only to colistin. Experiments to detect carbapenemases revealed the presence of the OXA-58 carbapenemase. Further analysis revealed the location of the bla OXA-58 gene on a $40 \mathrm{~kb}$ plasmid. To our knowledge, this is the first report of carbapenem resistance in A. baumannii isolates from Bolivia that is conferred by the OXA-58 carbapenemase. The presence of this gene in a multidrug-resistant clone and its location within a plasmid is of great concern with regard to the spread of carbapenem-resistant $A$. baumannii in the hospital environment in Bolivia.
\end{abstract}

\section{INTRODUCTION}

Acinetobacter baumannii is a nosocomial pathogen responsible for severe infections often diagnosed in patients attending hospitals worldwide. Carbapemens are considered the drugs of choice for treating these infections, but they are not always efficient due to the occurrence of multidrug-resistant strains of this bacterium (Canduela et al., 2006; Coelho et al., 2006; Higgins et al., 2010a; Mendes et al., 2009; Poirel et al., 2010). Mechanisms enabling the development of carbapenem resistance include an induced decrease in membrane permeability, efflux pump overexpression and the production of carbapenemases. Among these mechanisms, the production of carbapenemases plays a major role in carbapenem resistance in most Gram-negative bacilli, including A. baumannii clinical isolates (Canduela et al., 2006; Coelho et al., 2006; Poirel et al., 2010; Queenan \& Bush, 2007; Walsh, 2010). The most common type of enzyme occurring in A. baumannii is represented by the carbapenem-hydrolysing class $\mathrm{D} \beta$-lactamases, which are divided into five phylogenetic groups: OXA-23-like, OXA24-like, OXA-58-like, OXA-51-like, which is intrinsic to
A. baumannii, and the recently described OXA-143-like enzymes (Higgins et al., 2009; Queenan \& Bush, 2007).

Although A. baumannii is considered an emerging pathogen and much research has been carried out on it, there have been only a few studies concerning the mechanisms conferring carbapenem resistance of this bacterium in Latin American countries (Celenza et al., 2006; Coelho et al., 2006; Sader et al., 2004; Sgambatti et al., 2010). In addition, there are no previous publications regarding the resistance of $A$. baumannii to imipenem or the occurrence of carbapenemases in A. baumannii isolates in Bolivia.

In this study, we analysed the antibiotic resistance, in particular to imipenem, of clinical isolates of A. baumannii obtained from several hospitals in Cochabamba, Bolivia, and the presence of carbapenemases as a mechanism of resistance to imipenem in these strains.

\section{METHODS}

Bacterial isolates. Forty-three A. baumannii and three Acinetobacter genomic species 13TU, collected from March 2008 to July 2009 in the 
Microbiology Service of the Hospital Gastroenterológico BolivianoJaponés in Cochabamba, Bolivia, were analysed in this study. This hospital collects isolates from different hospitals of the city of Cochabamba: Hospital Viedma, Clínica Olivos and Hospital MaternoInfantil. They were identified using the API 32 system (bioMérieux) and the Phoenix System (Beckton Dickinson). Identification to species level was further confirmed by gyrB multiplex PCR (Higgins et al., 2010c).

Isolates were obtained from 46 patients (one isolate per patient), comprising 30 males and 16 females of different ages ranging from 1 day to 84 years, and were collected following conventional bacteriological culture techniques from different samples: 17 specimens from respiratory tract infections, 13 from wounds, four from blood cultures, four from catheter samples, three from urine samples and five from other samples.

Susceptibility testing. MICs were determined using the Phoenix System (Beckton Dickinson) according to current Clinical and Laboratory Standards Institute guidelines (CLSI, 2007). The antibiotics tested were: amikacin, gentamicin, tobramycin, trimethoprim/ sulfamethoxazole, amoxicillin/clavulanic acid, ampicillin, aztreonam, cefazolin, cefepime, cefoxitin, ceftazidime, ceftriaxone, cefuroxime, colistin, imipenem, meropenem, piperacillin/tazobactam, rifampicin, fosfomycin, nitrofurantoin and ciprofloxacin.

Molecular typing by PFGE. ApaI-digested genomic DNA was prepared according to the manufacturer's instructions (Bio-Rad) and restricted fragments were separated on a CHEF-DR II system (Bio$\mathrm{Rad})$ for $30 \mathrm{~h}$ at $14{ }^{\circ} \mathrm{C}$ with $5-35 \mathrm{~s}$ of linear ramping at $6 \mathrm{~V} \mathrm{~cm}{ }^{-1}$ (Turton et al., 2004). DNA fingerprints were analysed using Quantity One 1-D Analysis Software (Bio-Rad) following criteria described previously (Tenover et al., 1995).

$\beta$-Lactamase detection and sequencing experiments. Phenotypic detection of carbapenemases and metallo- $\beta$-lactamases was analysed by the Hodge test, and the Hodge test with zinc sulfate/ double disc synergy test, respectively (Lee et al., 2003). Extendedspectrum $\beta$-lactamases were determined by a double disc synergy test analysing the presence of synergy between discs of cephalosporins and inhibitors (Celenza et al., 2006).

Genotypic detection of carbapenemase genes was carried out by multiplex PCR amplifying blaxA-23-like, bla $a_{\mathrm{OXA}-24}$-like, $b$ laxA-51- $_{\text {OX }}$

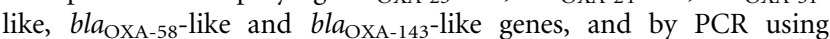
primers specific for the $b l_{\mathrm{IMP}}$ and $b l_{\mathrm{VIM}}$ genes, as described previously (Canduela et al., 2006; Higgins et al. 2010b; Woodford et al., 2006). Fragments corresponding to the entire coding region of $b l a_{\text {OXA-58 }}$ were sent for sequencing.

Presence of genetic class 1 integrons, insertion sequences and plasmids. PCR experiments were carried out to detect class 1 integrons (with primers corresponding to $3^{\prime}$ and $5^{\prime}$ conserved sequences) and insertion sequences IS $A b a-1,-2$ and -3 with specific primers, as described previously (Gallego \& Towner, 2001; Poirel et al., 2005). The relationship between $b l a_{\mathrm{OXA}-58}$ and the detected insertion sequences was determined using custom primers anchored in the oxacillinase-encoding genes and in the IS elements.

Extraction of plasmid DNA was carried out using a commercial kit following the manufacturer's instructions (Plasmid Midi kit; Qiagen). The size of the plasmids was determined by comparison with control strains of Escherichia coli NCTC 50193 and NCTC 59192, which contain plasmids ranging in size from 2 to $163.3 \mathrm{~kb}$, as described previously (Sevillano et al., 2009).

Location and characterization of the bla oxA-58 gene. Plasmid extractions separated on agarose gels were transferred to a nylon membrane and subsequently UV cross-linked and hybridized with a specific digoxygenin-dUTP-labelled $b l a_{\text {OXA-58 }}$ probe (Sambrook \& Russell, 2001).

\section{RESULTS AND DISCUSSION}

Determination of MICs showed that there was a high level of resistance to all antibiotics tested, with the exception of colistin. All isolates were resistant to aztreonam, cefazolin, cefoxitin, cefuroxime, fosfomycin and nitrofurantoin, and levels of resistance $>75 \%$ were detected to most of the other antibiotics tested. In contrast, all isolates remained susceptible to colistin (Table 1).

In our study, imipenem resistance was observed in $35 \%$ of isolates. This value was different from that obtained in a previous study carried out in hospitals in Santa Cruz (Bolivia), where carbapenem resistance was not found (Celenza et al., 2006). It was difficult to compare the results in this study with those in other regions due to the lack of published reports. However, the observed percentage of carbapenem-resistant isolates was similar to that found in 2004 in Argentina (39.3\%), Venezuela (36.4\%), Brazil (31.1\%) and Colombia (30.8\%) (Rossi et al., 2008; Sader et al., 2004; Sgambatti et al., 2010; Tognim et al., 2004). In contrast, our results were different from those found for carbapenem resistance in isolates in Chile (6.5\%), Mexico $(1.1 \%)$ or Guatemala, Honduras, Panama, Puerto Rico and Jamaica where no carbapenem-resistant isolates were found (Tognim et al., 2004). These percentages may have increased more recently as reported from hospitals in Puerto Rico, where imipenem-resistant isolates have emerged recently (Robledo et al., 2010). Reports from Asia-Pacific nations and Europe have revealed on average a lower percentage of carbapenem-resistant isolates (Mendes et al., 2009; Souli et al., 2008).

The clonal relatedness of the isolates enabled us to group them into four genotypes named A (15 isolates), B (eight isolates), $\mathrm{C}$ (nine isolates) and D (four isolates), in addition to unrelated single isolates. Comparisons of PFGE patterns with those from control strains belonging to European clones I, II and III showed no genetic relatedness. Analysis of their antibiotic resistance showed that (i) isolates from clone A were resistant to all antibiotics tested with the exception of colistin to which they remained susceptible and (ii) the majority of isolates belonging to groups B, C and D were susceptible only to carbapenems and colistin.

Molecular typing results indicated inter-hospital dissemination of carbapenem-resistant clone $\mathrm{A}$, as identical pulsotypes were identified in different institutions in Cochabamba. This fact is alarming, as there are only a few drugs that are clinically available to treat infections caused by this multidrug-resistant pathogen.

Class 1 integrons, ranging in size from 540 to $1100 \mathrm{bp}$, were present in all strains. The predominant band pattern was a combination of 540 and $780 \mathrm{bp}$ structures present in 32 isolates, in turn belonging to different groups. The 
Table 1. MICs $\left(\mu \mathrm{g} \mathrm{m}^{-1}\right)$ of antibiotics with in vitro activity against $A$. baumannii clinical isolates

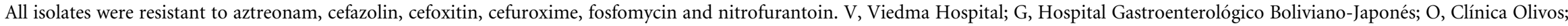
M, Hospital Materno-Infantil.

\begin{tabular}{|c|c|c|c|c|c|c|c|c|c|c|c|c|c|c|c|}
\hline \multirow[t]{2}{*}{ Antibiotic* } & \multicolumn{3}{|c|}{$\begin{array}{c}\text { Clone A (15 isolates: } \\
11 \mathrm{~V}, 2 \mathrm{G}, 2 \mathrm{O})\end{array}$} & \multicolumn{3}{|c|}{ Clone $B(8$ isolates: $6 \mathrm{~V}, 2 \mathrm{G})$} & \multicolumn{3}{|c|}{ Clone C (9 isolates: 6V, 3G) } & \multicolumn{3}{|c|}{ Clone $\mathrm{D}$ ( 4 isolates: $3 \mathrm{~V}, 1 \mathrm{M})$} & \multicolumn{3}{|c|}{$\begin{array}{l}\text { Other clones (7 isolates: } \\
\qquad 3 \mathrm{G}, 2 \mathrm{O}, 2 \mathrm{M})\end{array}$} \\
\hline & $\mathrm{MIC}_{50}$ & $\mathrm{MIC}_{90}$ & Range & $\mathrm{MIC}_{50}$ & $\mathrm{MIC}_{90}$ & Range & $\mathrm{MIC}_{50}$ & $\mathrm{MIC}_{90}$ & Range & $\mathrm{MIC}_{50}$ & $\mathrm{MIC}_{90}$ & Range & $\mathrm{MIC}_{50}$ & $\mathrm{MIC}_{90}$ & Range \\
\hline AMK & $>32$ & $>32$ & $>32->32$ & $\leqslant 8$ & $>32$ & $\leqslant 8->32$ & 32 & $>32$ & $32->32$ & $>32$ & $>32$ & $>32->32$ & $\leqslant 8$ & $>32$ & $\leqslant 8->32$ \\
\hline GEN & $>8$ & $>8$ & $>8->8$ & $>8$ & $>8$ & $>8->8$ & $>8$ & $>8$ & $4->8$ & $>8$ & $>8$ & $>8->8$ & $\leqslant 2$ & $>8$ & $\leqslant 2->8$ \\
\hline TOB & $>8$ & $>8$ & $>8->8$ & 8 & $>8$ & $\leqslant 2->8$ & $>8$ & $>8$ & $\leqslant 2->8$ & 8 & $>8$ & $8->8$ & $\leqslant 2$ & $>8$ & $\leqslant 2->8$ \\
\hline SXT & $>2 / 38$ & $>2 / 38$ & $1 / 19->2 / 38$ & $>2 / 38$ & $>2 / 38$ & $\leqslant 0.5 / 0.9-2 / 38$ & $>2 / 38$ & $>2 / 38$ & $>2 / 38-2 / 38$ & $>2 / 38$ & $>2 / 38$ & $\leqslant 0.5 / 0.9->2 / 38$ & $\leqslant 0.5 / 0.9$ & $>2 / 38$ & $\leqslant 0.5 / 0.9->2 / 38$ \\
\hline AMC & $>16 / 8$ & $>16 / 8$ & $>16 / 8$ & $>16 / 8$ & $>16 / 8$ & $16 / 8->16 / 8$ & $>16 / 8$ & $>16 / 8$ & $16 / 8->16 / 8$ & $>16 / 8$ & $>16 / 8$ & $>16 / 8->16 / 8$ & $16 / 8$ & $>16 / 8$ & $\leqslant 4 / 2->16 / 8$ \\
\hline AMP & $>16$ & $>16$ & $>16->16$ & $>16$ & $>16$ & $>16->16$ & $>16$ & $>16$ & $16->16$ & $>16$ & $>16$ & $>16->16$ & 16 & $>16$ & $\leqslant 4->16$ \\
\hline FEP & $>16$ & $>16$ & $>16->16$ & $>16$ & $>16$ & $4->16$ & $>16$ & $>16$ & $4->16$ & 16 & 16 & $16-16$ & 4 & $>16$ & $\leqslant 2->16$ \\
\hline CAZ & $>16$ & $>16$ & $>16->16$ & $>16$ & $>16$ & $2->16$ & $>16$ & $>16$ & $4->16$ & $>16$ & $>16$ & $>16->16$ & 4 & $>16$ & $2->16$ \\
\hline CRO & $>32$ & $>32$ & $>32->32$ & $>32$ & $>32$ & $8->32$ & $>32$ & $>32$ & $16->32$ & $>32$ & $>32$ & $>32->32$ & 16 & $>32$ & $4->32$ \\
\hline IPM & $>8$ & $>8$ & $>8->8$ & 2 & 2 & $\leqslant 1-2$ & $\leqslant 1$ & 2 & $\leqslant 1-2$ & 2 & 2 & $2-2$ & $\leqslant 1$ & $\leqslant 1$ & $\leqslant 1-\leqslant 1$ \\
\hline MEM & $>8$ & $>8$ & $8->8$ & $\leqslant 1$ & 8 & $\leqslant 1-8$ & $\leqslant 1$ & 2 & $\leqslant 1-8$ & $\leqslant 1$ & 4 & $\leqslant 1-4$ & $\leqslant 1$ & $\leqslant 1$ & $\leqslant 1-\leqslant 1$ \\
\hline $\mathrm{TZP}$ & $>64 / 4$ & $>64 / 4$ & $>64 / 4->64 / 4$ & $>64 / 4$ & $>64 / 4$ & $\leqslant 4 / 4->64 / 4$ & $64 / 4$ & $>64 / 4$ & $16 / 4->64 / 4$ & $>64 / 4$ & $>64 / 4$ & $16 / 4->64 / 4$ & $\leqslant 4 / 4$ & $64 / 4$ & $\leqslant 4 / 4->64 / 4$ \\
\hline CIP & $>2$ & $>2$ & $>2->2$ & $>2$ & $>2$ & $0.5->2$ & $>2$ & $>2$ & $>2->2$ & $>2$ & $>2$ & $>2->2$ & 1 & $>2$ & $\leqslant 0.125->2$ \\
\hline NOR & $>8$ & $>8$ & $>8->8$ & $>8$ & $>8$ & $\leqslant 2->8$ & $>8$ & $>8$ & $>8->8$ & $>8$ & $>8$ & $>8->8$ & 8 & $>8$ & $\leqslant 2->8$ \\
\hline CST & $<1$ & $<1$ & $<1-2$ & $\leqslant 1$ & $\leqslant 1$ & $\leqslant 1-2$ & $\leqslant 1$ & $\leqslant 1$ & $\leqslant 1-\leqslant 1$ & $\leqslant 1$ & $\leqslant 1$ & $\leqslant 1-\leqslant 1$ & $\leqslant 1$ & $\leqslant 1$ & $\leqslant 1-\leqslant 1$ \\
\hline RIF & 8 & 16 & $8-16$ & $>128$ & $>128$ & $>128->128$ & $>128$ & $>128$ & $16->128$ & 16 & $>128$ & $16->128$ & 16 & 16 & $8->128$ \\
\hline
\end{tabular}

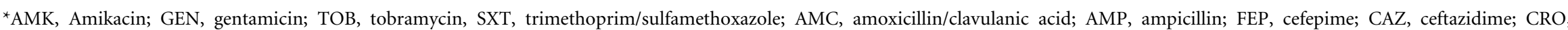
ceftriaxone; IPM, imipenem; MEM, meropenem; TZP, piperacillin/tazobactam; CIP, ciprofloxacin; NOR, norfloxacin; CST, colistin; RIF, rifampicin. 
presence of integrons occurring with high frequency in these clinical isolates could be related to the resistance to aminoglycosides, as the genes encoding aminoglycosideinactivating enzymes are often found on these genetic elements worldwide (Gallego \& Towner, 2001).

Plasmids were found in 35 isolates, ranging in size from 2 to $40 \mathrm{~kb}$. The most frequently detected genetic element was a $40 \mathrm{~kb}$ plasmid present in 15 isolates in group A (Fig. 1). Other plasmids of $2.5 \mathrm{~kb}$ (13 isolates), $11 \mathrm{~kb}$ (seven isolates), $5.8 \mathrm{~kb}$ (five isolates), $9 \mathrm{~kb}$ (two isolates), $28 \mathrm{~kb}$ (two isolates) and $14 \mathrm{~kb}$ (one isolate) were also detected.

As imipenem is the last therapeutic option when treating nosocomial infections caused by antibiotic-resistant $A$. baumannii isolates, we investigated further whether the presence of $\beta$-lactamases potentially expressed by these isolates could confer their resistance to imipenem. No extended-spectrum $\beta$-lactamase-producing isolates were detected in this study, although $b l a_{\text {CTX-M-type }}$ and $b l a_{\text {PER-2 }}$ genes were detected in a previous study carried out in Santa Cruz, another region of Bolivia (Celenza et al., 2006). This suggests that resistance to cephalosporins could be due to other mechanisms, such as the expression of chromosomal ADC $\beta$-lactamase, reduced membrane permeability caused by a decrease in expression of porin genes and/or an increase in the efficiency of efflux pumps.

Carbapenemase activity was detected in $70 \%$ of the isolates by the Hodge test, probably due to expression of the intrinsic OXA-51 carbapenemase or other acquired carbapenemases. Although they have been reported in $A$.

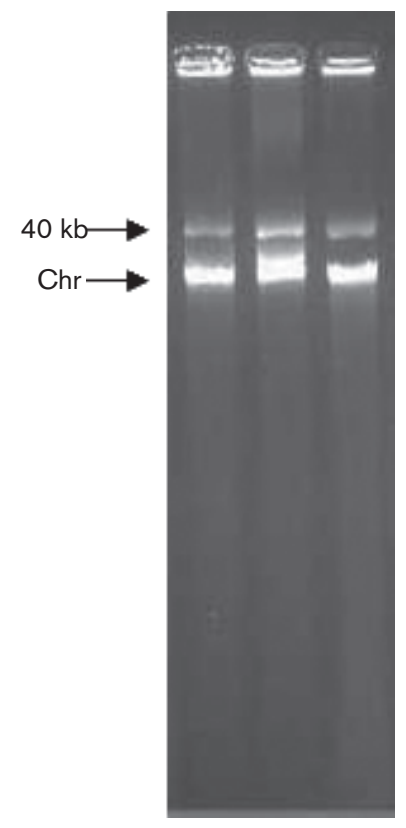

Fig. 1. Examples of the $40 \mathrm{~kb}$ plasmid DNA from different isolates belonging to clone A. The chromosomal DNA (Chr) is also indicated. baumannii from other Latin American countries (Sader et al., 2005), further PCR experiments detected no metallo$\beta$-lactamase genes in our isolates.

The multiplex PCR detected the presence of the $b l a_{\mathrm{OXA}-51^{-}}$ like gene in all A. baumannii strains except three isolates that were subsequently identified to be Acinetobacter $13 \mathrm{TU}$ by the gyrB multiplex PCR. In addition, an amplification band corresponding to the $b a_{\text {OXA-58 }}$ gene was detected in all isolates of the multidrug-resistant clone A group. Sequencing of the 843 bp amplicon showed $100 \%$ identity with the $b l a_{\text {OXA-58 }}$ gene sequence described previously (Poirel et al., 2005) and the presence of an ISAba-3 element. Southern blot analysis with a $b a_{\mathrm{OXA}-58}$-specific probe generated by PCR enabled us to localize this gene on the $40 \mathrm{~kb}$ plasmid. This plasmid was within the size range (10-150 kb) described by other authors (Bertini et al., 2006; Héritier et al., 2005; Marqué et al., 2005; Poirel et al., 2005; Wang et al., 2007).

Although the $b a_{\text {OXA-58 }}$ gene has also been detected in isolates from other Latin American countries, we believe that this is the first report of this gene in Bolivian clinical isolates. Our results support previous reports indicating the worldwide spread of the $b l a_{\mathrm{OXA}-58}$ gene and highlight its importance in conferring carbapenem resistance among A. baumannii isolates from Latin America (Coelho et al., 2006; Higgins et al., 2010a; Kulah et al., 2010; Marqué et al., 2005; McCracken et al., 2009; Mendes et al., 2009; Papa et al., 2009).

In conclusion, this is the first report, to our knowledge, of carbapenem resistance in A. baumannii isolates from Bolivia associated with the presence of the $b a_{\text {OXA-58 }}$ gene. Detection of the antibiotic-inactivating enzyme in a multidrug-resistant clone and its expression is of great concern with regard to the spread of carbapenem resistance among hospitals in Bolivia.

\section{ACKNOWLEDGEMENTS}

We would like to thank Dr Jenny Pinto, Dr Fatima Funes and Dr Jenny Zamora from the Facultad de Bioquímica y Farmacia Cochabamba (Bolivia) for their assistance. We are also grateful to Dr Ramón Cisterna, Aurora Morla and Olvido Hernández from the Microbiology Service of Hospital de Basurto (Bilbao, Spain) for their help with the antibiotic analysis and Dr Vladimir Kaberdin (University of the Basque Country, Spain) and Bruno S. Lopes (Centre for Infectious Diseases, University of Edinburgh, UK) for critically reading the manuscript. This work has been supported by the AECID (Agencia Española de Cooperación y Desarrollo), Ministerio de Asuntos Exteriores, Spain (grant A/9758/07) and by a grant from the Oficina de Cooperación al Desarrollo, Vicerrectorado de Relaciones Internacionales (University of the Basque Country, Spain).

\section{REFERENCES}

Bertini, A., Giordano, A., Varesi, P., Villa, L., Mancini, C. \& Carattoli, A. (2006). First report of the carbapenem-hydrolyzing oxacillinase OXA-58 in Acinetobacter baumannii isolates in Italy. Antimicrob Agents Chemother 50, 2268-2269. 
Canduela, M. J., Gallego, L., Sevillano, E., Valderrey, C., Calvo, F. \& Pérez, J. (2006). Evolution of multidrug-resistant Acinetobacter baumannii isolates obtained from elderly patients with respiratory tract infections. J Antimicrob Chemother 57, 1220-1222.

Celenza, G., Pellegrini, C., Caccamo, M., Segatore, B., Amicosante, G. \& Perilli, M. (2006). Spread of $b l a_{\text {CTX-M-type }}$ and $b l a_{\text {PER-2 }} \beta$-lactamase genes in clinical isolates from Bolivian hospitals. J Antimicrob Chemother 57, 975-978.

CLSI (2007). Methods for Dilution Antimicrobial Susceptibility Tests for Bacteria That Grow Aerobically, 7th edn; Approved Standard. M7-A7. Wayne, PA, USA: Clinical and Laboratory Standards Institute.

Coelho, J., Woodford, N., Afzal-Shah, M. \& Livermore, D. (2006). Occurrence of OXA-58-like carbapenemases in Acinetobacter spp. collected over 10 years in three continents. Antimicrob Agents Chemother 50, 756-758.

Gallego, L. \& Towner, K. J. (2001). Carriage of class 1 integrons and antibiotic resistance in clinical isolates of Acinetobacter baumannii from northern Spain. J Med Microbiol 50, 71-77.

Héritier, C., Dubouix, A., Poirel, L., Marty, N. \& Nordmann, P. (2005). A nosocomial outbreak of Acinetobacter baumannii isolates expressing the carbapenem-hydrolysing oxacillinase OXA-58. J Antimicrob Chemother 55, 115-118.

Higgins, P. G., Poirel, L., Lehmann, M., Nordmann, P. \& Seifert, H. (2009). OXA-143, a novel carbapenem-hydrolyzing class D $\beta$ lactamase in Acinetobacter baumannii. Antimicrob Agents Chemother 53, 5035-5038.

Higgins, P. G., Dammhayn, C., Hackel, M. \& Seifert, H. (2010a). Global spread of carbapenem-resistant Acinetobacter baumannii. J Antimicrob Chemother 65, 233-238.

Higgins, P. G., Lehmann, M. \& Seifert, H. (2010b). Inclusion of OXA-143 primers in a multiplex polymerase chain reaction (PCR) for genes encoding prevalent OXA carbapenemases in Acinetobacter spp. Int J Antimicrob Agents 35, 305.

Higgins, P. G., Lehmann, M., Wisplinghoff, H. \& Seifert, H. (2010c). gyrB multiplex PCR to differentiate between Acinetobacter calcoaceticus and Acinetobacter genomic species 3. J Clin Microbiol 48, 45924594.

Kulah, C., Mooij, M. J., Comert, F., Aktas, E., Celebi, G., Ozlu, N., Rijnsburger, M. C. \& Savelkoul, P. H. M. (2010). Characterisation of carbapenem-resistant Acinetobacter baumannii outbreak strains producing OXA-58 in Turkey. Int J Antimicrob Agents 36, 114-118.

Lee, K., Lim, Y. S., Yong, D., Yum, J. H. \& Chong, Y. (2003). Evaluation of the Hodge test and the imipenem-EDTA double-disk synergy test for differentiating metallo- $\beta$-lactamase-producing isolates of Pseudomonas spp. and Acinetobacter spp. J Clin Microbiol 41, 4623-4629.

Marqué, S., Poirel, L., Héritier, C., Brisse, S., Blasco, M. D., Filip, R., Coman, G., Naas, T. \& Nordmann, P. (2005). Regional occurrence of plasmid-mediated carbapenem-hydrolyzing oxacillinase OXA-58 in Acinetobacter spp. in Europe. J Clin Microbiol 43, 4885-4888.

McCracken, M., DeCorby, M., Fuller, J., Loo, V., Hoban, D. J., Zhanel, G. G. \& Mulvey, M. R. (2009). Identification of multidrug- and carbapenem-resistant Acinetobacter baumannii in Canada: results from CANWARD 2007. J Antimicrob Chemother 64, 552-555.

Mendes, R. E., Bell, J. M., Turnidge, J. D., Castanheira, M. \& Jones, R. N. (2009). Emergence and widespread dissemination of OXA-23, 24/40 and -58 carbapenemases among Acinetobacter spp. in AsiaPacific nations: report from the SENTRY Surveillance Program. J Antimicrob Chemother 63, 55-59.

Papa, A., Koulourida, V. \& Souliou, E. (2009). Molecular epidemiology of carbapenem-resistant Acinetobacter baumannii in a newly established Greek hospital. Microb Drug Resist 15, 257-260.
Poirel, L., Marqué, S., Héritier, C., Segonds, C., Chabanon, G. \& Nordmann, P. (2005). OXA-58, a novel class D $\beta$-lactamase involved in resistance to carbapenems in Acinetobacter baumannii. Antimicrob Agents Chemother 49, 202-208.

Poirel, L., Naas, T. \& Nordmann, P. (2010). Diversity, epidemiology, and genetics of class D $\beta$-lactamases. Antimicrob Agents Chemother 54, 24-38.

Queenan, A. M. \& Bush, K. (2007). Carbapenemases: the versatile $\beta$-lactamases. Clin Microbiol Rev 20, 440-458.

Robledo, I. E., Aquino, E. E., Santé, M. I., Santana, J. L., Otero, D. M., León, C. F. \& Vázquez, G. J. (2010). Detection of KPC in Acinetobacter spp. in Puerto Rico. Antimicrob Agents Chemother 54, 1354-1357.

Rossi, F., García, P., Ronzon, B., Curcio, D. \& Dowzicky, M. J. (2008). Rates of antimicrobial resistance in Latin America (2004-2007) and in vitro activity of the glycylcycline tigecycline and of other antibiotics. Braz J Infect Dis 12, 405-415.

Sader, H. S., Jones, R. N., Gales, A. C., Silva, J. B., Pignatari, A. C. \& SENTRY Participants Group (Latin America) (2004). SENTRY antimicrobial surveillance program report: Latin American and Brazilian results for 1997 through 2001. Braz J Infect Dis 8, 25-79.

Sader, H. S., Castanheira, M., Mendes, R. E., Toleman, M., Walsh, T. R. \& Jones, R. N. (2005). Dissemination and diversity of metallo- $\beta$ lactamases in Latin America: report from the SENTRY Antimicrobial Surveillance Program. Int J Antimicrob Agents 25, 57-61.

Sambrook, J. \& Russell, D. W. (2001). Molecular Cloning: a Laboratory Manual, 3rd edn. Cold Spring Harbor, NY: Cold Spring Harbor Laboratory.

Sevillano, E., Gallego, L. \& García-Lobo, J. M. (2009). First detection of the OXA-40 carbapenemase in P. aeruginosa isolates, located on a plasmid also found in A. baumannii. Pathol Biol (Paris) 57, 493-495.

Sgambatti, S., Gales, A. C. \& Sader, H. S. (2010). Antimicrobial resistance in Gram-negative bacteria from developing countries. In Antimicrobial Resistance in Developing Countries, pp. 249-266. Edited by A. De J Sosa, D. K. Byarugaba, C. F. Amábile-Cuevas, P. R. Hsueh, S. Kariuki \& I. N. Okeke. New York, Dordrecht, Heidelberg, London: Springer.

Souli, M., Galani, I. \& Giamarellou, H. (2008). Emergence of extensively drug-resistant and pandrug-resistant Gram-negative bacilli in Europe. Euro Surveill 13, 1-11.

Tenover, F. C., Arbeit, R. D., Goering, R. V., Mickelsen, P. A., Murray, B. E., Persing, D. H. \& Swaminathan, B. (1995). Interpreting chromosomal DNA restriction patterns produced by pulsed-field gel electrophoresis: criteria for bacterial strain typing. J Clin Microbiol 33, 2233-2239.

Tognim, M. C. B., Andrade, S. S., Silbert, S., Gales, A. C., Jones, R. N. \& Sader, H. S. (2004). Resistance trends of Acinetobacter spp. in Latin America and characterization of international dissemination of multidrug resistant strains: five-year report of the SENTRY Antimicrobial Surveillance Program. Int J Infect Dis 8, 284-291.

Turton, J. F., Kaufmann, M. E., Warner, M., Coelho, J., Dijkshoorn, L., van der Reijden, T. \& Pitt, T. L. (2004). A prevalent, multiresistant clone of Acinetobacter baumannii in Southeast England. J Hosp Infect 58, 170-179.

Walsh, T. R. (2010). Emerging carbapenemases: a global perspective. Int J Antimicrob Agents 36 (Suppl. 3), S8-S14.

Wang, H., Guo, P., Sun, H., Wang, H., Yang, Q., Chen, M., Xu, Y. \& Zhu, Y. (2007). Molecular epidemiology of clinical isolates of carbapenem-resistant Acinetobacter spp. from Chinese hospitals. Antimicrob Agents Chemother 51, 4022-4028.

Woodford, N., Ellington, M. J., Coelho, J. M., Turton, J. F., Ward, M. E., Brown, S., Amyes, S. G. \& Livermore, D. M. (2006). Multiplex PCR for genes encoding prevalent OXA carbapenemases in Acinetobacter spp. Int J Antimicrob Agents 27, 351-353. 